\title{
The simultaneous determination of cash conversion cycle components
}

\author{
Georgios Kolias $^{\mathrm{a}, 1}$ Nikolaos Arnis ${ }^{\mathrm{a}}$ and Kostas Karamanis ${ }^{\mathrm{a}}$ \\ ${ }^{a}$ University of Ioannina, Preveza, Greece
}

\begin{abstract}
Research Question: What are the interaction effects and links between the cash conversion cycle components? Motivation: One of the major difficulties in studying the links between the components of the cash conversion cycle is the fact that each of them is a determinant of the others. Idea: We develop a model to define the direction of the relations between cash conversion cycle components taking into consideration the contemporaneous correlation between them. Data: For the purposes of our study we use a balance panel dataset from Greek wholesale sector over the period 2005 - 2014. Tools: Error components three-stage least squares estimation for simultaneous equations of panel data is used. Findings: Our results show that inventory, accounts receivable and accounts payable are mutually endogenous factors and identify the causal relationships. We find that not only accounts payable lead to an increase in accounts receivable, but also accounts receivable leads to an increase in accounts payable. We argue that the causes for the effect of receivables on inventory differ from that of inventory on receivables. Contribution: The results of this study would be useful for wholesalers and supply chain managers to analyze and identify the interactions of inventory and trade credit policies. Moreover, our model can be used for the more accurate forecasting of inventory, accounts receivable and accounts payable.
\end{abstract}

Keywords: finance; cash conversion cycle; simultaneous equations model

JEL codes: C33, L21, M41

1 Corresponding Author: Georgios Kolias, University of Ioannina, Department of Accounting \& Finance, Preveza, 48100, Greece; email addresses: koliasg@otenet.gr, narnis@uoi.gr,kkaraman@uoi.gr 


\section{Introduction}

Working capital management involves the management of the relationships between firm's short-term assets and short-term liabilities. Hill et al. (2010) argue that operating and financing conditions must be taken into account when assessing the behavior of working capital and not just industry averages. Cash conversion cycle reflects the impact of these policies in firm liquidity and profitability. Additionally, the cash conversion cycle represents a fundamental feature of a company's operations, i.e. it explicitly recognizes that the four basic business activities (purchase or production, sales, collection and payments) generate firm's cash inflows and outflows (Wang, 2019). However, according to Zeidan \& Shapir (2017) there is no general model that optimizes working capital investments. Authors state that managing cash conversion cycle components, e.g. inventories, accounts payables, and accounts receivables, can distinctly improve the return on working capital investments, in particular, if a firm can do this without experiences lost sales.

One of the major difficulties in studying the links between the cash conversion cycle components is that the level of each one is the outcome of the simultaneous effect of the others. The result of these concurrent effects is that inventories, accounts receivable and accounts payable are each of them endogenous factor in determining the others. This situation has the following consequences in the study of their relationships if they are based on data derived from financial statements: i) usual regression analysis may be not the adequate technique in determining these causal effects. For example, a positive correlation between inventories and accounts payable, which can be calculated by simple statistical methods, does not effectively define the direction of the relationship in the sense that no conclusion can be drawn as to whether the increase in inventories is the determinant that leads to an increase in accounts payable and not the opposite, or that the two variables are identified by other factors at the same time, ii) changes in one variable may cause changes to the other two so that the validity of the overall working capital strategy evaluation is undermined, and iii) any attempt to predict a value of one variable is inappropriate if the effect of the others has not been accounted for.

In this paper, to study the simultaneous determination of the level of inventories, receivables and payables, a simultaneous equations model for panel data is developed. More specifically, an advanced 3SLS technique for panel data simultaneous equations system is used to evaluate the interaction effects of cash conversion cycle components. To our best knowledge there is no empirical study to jointly determine inventory and credit policies as they are proxied by the components of cash conversion cycle. For the scope of the study we use a large sample of Greek wholesale firms operating in the period 2005-2014. For many reasons wholesaling industry deserves great attention of practitioners and also is an 
interesting subject for academics. The main reason is that they integrate the twin operations of manufacturing and selling and run their business as both manufacturers and wholesalers. Thus, wholesalers have the ability to making goods widely accessible and available to target markets (Kotler, 1980).

In this study we estimate the causal effects among, working capital components. We provide new evidence of the interrelationship between inventory, accounts receivable and accounts payable. We find that not only accounts payable lead to an increase in accounts receivable, but also accounts receivable leads to an increase in accounts payable. This paper demonstrates that the causes for the effect of receivables on inventory differ from that of inventory on receivables. Specifically, the only negative effect observed among the variables was that of the receivables to inventories. At the same time, an increase in inventories cause an increase in accounts receivables.

Finally, we show that the reduced form model enables us to forecast inventory accounts receivables and accounts payables from historical data taking into consideration the interrelationships among them. The results of this study would be useful for wholesale and supply chain managers to analyze and determine the interrelations of inventory and trade credit policies.

The rest of this paper is organized as follows: In Section 2 we review the relevant literature. Section 3 presents the data and defines the variables used. In this section, we also discuss the econometric issues of the simultaneous equations model. Section 4 reports the estimations and presents the discussions of the results. We conclude the paper in section 5 with directions for future research.

\section{Literature review}

Wholesalers provide services to manufacturers/producers and also to retailers. Services to manufacturers include achieving benefits of economies of large-scale production, providing information about consumer behaviour and enable manufacturers to reduce working capital expenditures by decreasing inventory levels. Wholesalers serve retailers by providing trade credit and by allowing retailers to receive inventories faster than they could by placing orders directly on manufacturers (minimizing lead time).

Therefore, because firms do not operate in isolation but are bound by the structure of the networks into which they are embedded, this structure affects the ability of them to access resources and exploits them to their advantage (Carnovale et al., 2019). However, managers need to spend significant resources on working capital management to ensure the smooth running of their business (Adhikari et al., 2019). According to Jia et al. (2019), during the last financial crisis, businesses and their supply chain partners have limited cash flow and have found it difficult to get 
funding from banks. To address this adverse situation, supply chain agents try to minimize working capital requirements, to cut interest expenses and reduce their debt ratios through financial mechanisms to funding firms accounts receivable portfolio. As a result, supply chain financing practices are come into view and allow firms to exploit the participation in supply chain to optimize working capital (Caniato et al., 2016). Therefore, these actions cause the levels of the cash conversion cycle components to fluctuate and interact with each other during the cash conversion period, determining the firm position regarding its liquidity and profitability.

Classical cash conversion cycle theory ${ }^{1}$ affirms that effective working capital management (i.e. a short cash conversion cycle) will increase business liquidity, profitability and value, while inefficient working capital management (i.e. a large cash conversion cycle) will lead to lower profitability and lower value of the business. However, more recent studies argue that there is an optimal level of working capital investment. Aktas et al. (2007) state that as companies approach this optimal level increasing or decreasing their investment in working capital, they improve their returns and operating performance over the next period. Moreover, Zeidan \& Shapir, (2017) indicate that cash conversion cycle management, controlling for effects on operating margins, increase cash flow and result in higher stock returns and profitability ratios. Whatever the case, the information provided by cash conversion cycle is using for measuring and judging the effectiveness of working capital management. This information proxies the behavior of firms' operating cash flows. Management of cash flows is a primary activity of firm that determines the investment in cash and receivables as well as in fixed assets and inventories. In the course of its business, the business generates cash as it sells its products or merchandise, while on the other hand it consumes cash as it purchases goods or pay its suppliers. Morris (1984) proposed a cash flow model relied in a single period CAPM valuation framework. The idea behind, is that the negative net cash flows should be financed either from existing cash balances or by using external funds. This proposition is consistent with cash pecking order theory (Opler \& Pinckowich, 1990). This process highlights the correlation between operations and finance (Birge et al., 2007; Gupta \& Dutta, 2001). However firms are not always able to predict the result from both the financial and operational policy. Clearly, there are trade-offs involved in these activities. Operations managers make operational decisions about working capital requirements, while financial managers make at the same time arbitrary decisions about the desired financial performance and thus inevitably limit their operational performance. (ProtopappaSieke \& Seifert, 2010).

Additionally many studies analyze the relations between inventory management and credit policies. Kim and Chung (1990) state that optimal results cannot be obtained when these interrelated policy variables are formulated independently 
while joint inventory and credit management provide a desired direction to a decision.

Bougheas et al. (2009) argue that firms which face uncertain demand they prefer to offer trade credit to its customers and boost demand rather than accumulate costly inventories. The results of their study indicate that there is a direct impact of inventories on accounts receivable. However, the influence of inventories on accounts payable is insubstantial. Kolias and Arnis (2019) develop a framework that encompasses these decisions by taking into consideration the trade-off between risk and return. They build up a two stages model. In the first stage, using panel data techniques, the estimates of the expected returns and standard deviations for cash holdings, inventories and receivables along with the correlations between them are obtained. Using these estimates, in the second stage they employ meanvariance analysis to determine the optimal allocation of current assets portfolio and construct the efficient frontier of the possible combinations of the current assets' elements.

The incentive of businesses to extend credit to their customers so as accounts receivable and accounts payable appear in their balance sheets is well analyzed in literature related to trade credit as well as to working capital management. According to Gentry and De La Garza (1990) there are certain conditions that potentially affect the level of accounts payable. These conditions are determined by the combined effect of the intensity and conditions of supply of credit on the part of suppliers with the intensity of demand and the process of repayment of liabilities by buyers. Petersen and Rajan (1997) indicate that large firms are offered more trade credit because they are better borrowers (they are more likely to repay their debt obligations on time. Hence, the firm size represents a significant determinant of trade credit.

Money market imperfections explain not only the behavior of businesses to hold cash but also the motivation that drives firms to extend trade credit to their customers. In a sense, businesses that provide loans to their customers transfer (invest) their excess liquidity into financial constrained buyers that have difficulties borrowing from banks. If the demand for trade credit is interpreted as a component of the general business lending policy then it should be taken into account as a dimension in identifying the factors that affect it and the growth opportunities of the business. It can be assumed that the greater the growth potential of the business the greater the demand for commercial credit or the increase in the level of accounts payable. The degree of growth opportunities can be proxied by the ratio of net fixed assets to accumulated depreciation.

Ferrando and Mulier (2013) examine whether firms are actively using accounts payable and accounts receivable to manage their growth. They argue that it is not only the accounts payable but also the accounts receivable that matter. While the 
former help reduce the financial market imperfections, the latter do so in the product market.

The above studies indicate the complexity of the relationship between the determinants of inventory, receivables and payables management. Therefore, independent least square estimation of regression equations of cash conversion components on the independent variables would produce parameters that are inconsistent because inventories, receivables and payables are contemporaneously correlated. That would necessitate the development of a simultaneous financial planning model allowing the measurement and interpretation of the concurrent determination of cash conversion cycle features.

The determinants of inventory behaviour have been analyzed in many empirical studies in accounting, finance and operations research literature indicate the more important factors affect inventory levels. Gaur et al. (2005), Kolias et al. (2011) Rajagopalan (2013), Johnston (2011), Rumyantsev and Netessine (2007) and Lee et al. (2015) support the hypothesis that inventory turnover ratio is correlated with gross margin, capital intensity and with measures of sales surprise. Complete definitions of all variables that can be used in studying the relationships of cash conversion cycle features are provided in section 3.

\section{Data presentation and model specification}

Following the review of the literature in the above section, initially we specify the equations that represent the behaviour of inventories, accounts payable and accounts receivable. Next, we model the interrelationships of the three components by developing a simultaneous equation approach for panel data.

\subsection{Inventories equation}

Inventories equation defines the factors affecting inventories holding period

$$
D I H=f\left(D I H_{t-1}, \text { cint }, g m, s s, D S O, D P O\right)
$$

The structure of the equation is as follows:

\section{I) Dependent variable:}

DIH (Days Inventories Held). This index measures how fast inventory is turning over:

$$
D I H_{i t}=\frac{365 \cdot i n v_{i t}}{c g s_{i t}}
$$


Where $c g s_{t}$ is the cost of goods sold at time $\boldsymbol{t}$, and $i n v_{t}$ is the inventories' level at time $t$, with $t=2005, . ., 2014$ the available years of the data set for each firm $\boldsymbol{i}$.

\section{II) Independed exogenous variables:}

1. The dependent variable with a time lag : $\boldsymbol{D} \boldsymbol{I} \boldsymbol{H}_{\boldsymbol{i}, \boldsymbol{t}-\mathbf{1}}$

2. Capital Intensity (cint) is defined as the ratio of net fixed assets (NFA) to the sum of inventories (inv) and net fixed assets $(N F A)$ at year $t$ :

$$
\operatorname{cint}_{i t}=\frac{N F A_{i t}}{N F A_{i t}+i n v_{i t}}
$$

3. Gross margin (gm) is the ratio of sales minus cost of goods sold at year $t$ to sales at year t:

$$
g m_{i t}=\frac{\text { sales }_{i t}-c g s_{i t}}{\text { sales }_{i t}}
$$

4. Sales Surprise (ss). This index is defined as the ratio of actual sales to anticipated sales (SalesForecast).

$$
s s_{i t}=\frac{\text { sales }_{\text {it }}}{\text { SalesForecast }_{i t}}
$$

Because sales' forecasts are not publicly reported, the estimation of SalesForecast is based on historical data and is performed by using Holt's linear exponential smoothing method. The SalesForecast for year $t$ is:

$$
\text { SalesForecast }_{i t}=L_{i, t-1}+T_{i, t-1}
$$

where $L_{i, t-1}$ and $T_{i, t-1}$ are smoothed series defined as

$$
\begin{gathered}
L_{i, t-1}=\alpha . \text { sales }_{i t}+(1-a)\left(L_{i t}+T_{i t}\right) \\
T_{i, t-1}=\beta \cdot\left(T_{i t}-L_{i, t-1)}\right)+(1-\beta) T_{i, t-1}
\end{gathered}
$$

and $a, \beta\{\alpha, \beta \in[0.6,0.4]\}$ are constant weights. We test many values of $\alpha$ and $\beta$ and ended up to these which minimize the forecasting errors.

\section{III) Endogenous variables:}

1. Days Sales Outstanding (DSO). This index measures how long it takes for a company to get paid when its customers buy on credit:

$$
D S O_{i t}=\frac{365 \cdot R E C_{i t}}{\text { sales }_{i t}}
$$


Where sales $_{t}$ is the volume of sales at time $t$, and $R E C_{t}$ is the receivables' level at time $t$.

2. Days Payables Outstanding (DPO) it measures how long it takes for a company to pay its suppliers:

$$
D P O_{i t}=\frac{365 . P A Y_{i t}}{c g s_{i t}}
$$

Where $P A Y_{t}$ is the payables' level at time $t$.

\subsection{Receivables equation}

Receivables equation defines the factors affecting Days Sales Outstanding period

$$
D S O=f\left(D O_{t-1}, \text { oldassets, } D I H, D P O\right)
$$

The structure of the equation is as follows:

\section{I) Dependent Variable:}

Days Sales Outstanding (DSO), as it defined previously

II) Independent Variables:

1. The dependent variable with a time lag: $\boldsymbol{D S} \boldsymbol{O}_{\boldsymbol{i}, \boldsymbol{t}-\mathbf{1}}$

2. Degree of growth opportunities (oldassets). This index is defined as the ratio of net fixed assets (NFA) to accumulated depreciation appears on the balance sheet (depr). This variable accounts for the age of fixed assets.

$$
\text { oldassets }_{i t}=\frac{N F A_{i t}}{\operatorname{depr}_{i t}}
$$

\section{III) Endogenous variables:}

1. Days Inventories Held (DIH).

2. Days Payables Outstanding (DPO)

\subsection{Payables equation}

Receivables equation defines the factors affecting Days Payables Outstanding period

$$
D P O=f\left(D P O_{t-1}, \text { size }, D I H, D S O\right)
$$


The structure of the equation is as follows:

\section{I) Dependent Variable: \\ Days Payables Outstanding (DPO) \\ II) Independent Variables:}

1. The dependent variable with a time lag: $\boldsymbol{D P} \boldsymbol{O}_{\boldsymbol{i}, \boldsymbol{t}-\mathbf{1}}$

2. The size of total assets (size)

\section{III) Endogenous variables:}

1. Days Inventories Held (DIH).

2. Days Sales Outstanding (DSO)

\subsection{Data presentation}

We present the distribution of the selected firms by subsector of economic activity in the appendix of the paper. For the purposes of our study we use financial data from Greek wholesale firms, drawn from their annual income statements and balance sheets. Firms are classified into the wholesale sector for the years 2005 to 2014. We use a balance panel contains 8240 observations across 824 publicly and privately held firms.

From the universe of publicly and privately held firms at Greece Wholesale sector of 40000 firm-year observations, we analyze 8240 observations across 824 firms constituting a panel data set. These missing data are caused by existing firms getting removed because they appeared with missing observations due to data unavailability, bankruptcy, mergers, acquisitions, liquidations, etc. Moreover, when new firms entering to the industry during the examining period are also excluded because they don't have available data for the whole period. We therefore exclude from our analysis all firms without complete data for the entire period of interest. We chose a balanced panel analysis to overcome several problems caused to the estimation procedure due to unbalanced data.

Table 1. Means of the variables for the period 2005-2013 for the Greek wholesale sector

\begin{tabular}{ccccccccc}
\hline year & DIH & DSO & DPO & ss & gm & cint & oldassets & size \\
\hline 2005 & 109.12 & 164.12 & 125.02 & 0.958 & 0.273 & 0.329 & 1.655 & 15.174 \\
2006 & 108.35 & 164.08 & 127.67 & 1.042 & 0.276 & 0.329 & 1.552 & 15.298 \\
2007 & 106.57 & 165.64 & 126.29 & 1.094 & 0.279 & 0.326 & 1.530 & 15.414 \\
2008 & 114.55 & 171.33 & 128.39 & 1.040 & 0.281 & 0.341 & 1.567 & 15.501 \\
2009 & 138.41 & 198.13 & 142.74 & 0.870 & 0.287 & 0.354 & 1.557 & 15.492 \\
2010 & 151.01 & 210.91 & 151.83 & 0.864 & 0.289 & 0.363 & 1.262 & 15.444
\end{tabular}


The simultaneous determination of cash conversion cycle components

\begin{tabular}{ccccccccc}
\hline year & DIH & DSO & DPO & ss & gm & cint & oldassets & size \\
\hline 2011 & 160.79 & 219.49 & 155.11 & 0.902 & 0.290 & 0.366 & 1.082 & 15.383 \\
2012 & 175.40 & 230.91 & 157.15 & 0.961 & 0.284 & 0.379 & 0.976 & 15.302 \\
2013 & 171.83 & 216.42 & 146.76 & 1.183 & 0.284 & 0.383 & 0.937 & 15.271 \\
2014 & 163.08 & 201.23 & 138.38 & 1.476 & 0.285 & 0.383 & 0.884 & 15.284 \\
\hline
\end{tabular}

Table 2 presents the means of the variables across years. The table shows that from 2008 onwards the average period of inventories, receivables and payables have increased significantly, possibly due to the impact of last financial crisis.

Table 2. Correlation matrix for the endogenous variables DIH, DSO and DPO

\begin{tabular}{lccc}
\hline & DIH & DSO & DPO \\
\hline DIH & 1 & & \\
DSO & $0.223^{*}$ & 1 & \\
DPO & $0.333^{*}$ & $0.494^{*}$ & 1 \\
\hline
\end{tabular}

$* \mathrm{p}<0.05, * * \mathrm{p}<0.01, * * * \mathrm{p}<0.001$

Table 3 shows the correlations among the endogenous variables. There is a positive relation between DIH, DSO and DPO

Figure 1 depicts the trend of the mean of the endogenous variables over the period 2004 to 2014. The turning point is clearly visible in the year 2008 for all of the dependent variables.

Figure 1. Trend of the mean of Days Inventory Holding (DIH), Days Sales Outstanding (DSO) and Days Payables Outstanding (DPO) over the period 2004 to 2014.

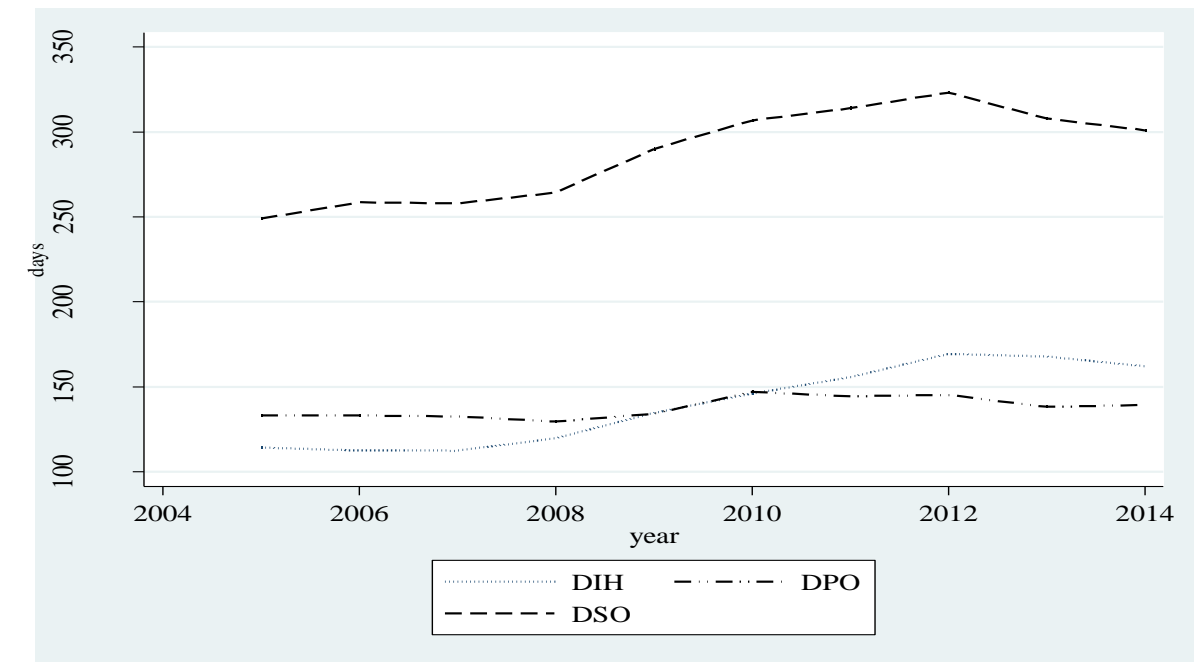




\subsection{Model specification}

The equations for inventories, accounts payable and accounts receivable are based on the previous sections where the determinants were analyzed. We note that since our interest focuses on the effect of time and on the dynamic aspect of working capital management, the use of variables that incorporate time effect is the most appropriate practice. Thus, we use the DIH, DSO and DPO as calculated in the relevant sections as endogenous variables of the system of simultaneously determined equations. In addition, we consider that log-log linear models express, in the most appropriate way, the relations between the components of the working capital.

We call S1 the equation of inventories and define it as follows:

$$
\begin{aligned}
\log D I H_{i t}=F_{i} & +b_{11} \log D S O_{i t}+b_{12} \log D P O_{i t}+b_{13} \operatorname{loggm}_{i t}+b_{14} \log c i n t_{i t} \\
& +b_{15} \log S s_{i t}+b_{16} \log D I H_{i, t-1}+u_{i t}
\end{aligned}
$$

The equation of accounts receivable, $\mathrm{S} 2$, is determined as follows:

$$
\begin{aligned}
\log \mathrm{DSO}_{i t}=S_{i} & +b_{21} \log \mathrm{DPO}_{i t}+b_{22} \log \mathrm{DHI}_{i t}+b_{23} \text { logoldassets }_{i t} \\
& +b_{24} \log \mathrm{DSO}_{i, t-1}+\eta_{i t}
\end{aligned}
$$

We call the equation of accounts payable S3 and define it as follows:

$$
\begin{aligned}
\log D P O_{i t}=P_{i} & +b_{31} \log D S O_{i t}+b_{32} \log D H I_{i t}+b_{33} \log \operatorname{size}_{i t}+b_{34} \log D P O_{i, t-1} \\
& +e_{i t}
\end{aligned}
$$

The system of the above equations apart from the coefficients of the endogenous and control variables and the residuals of the equations $u_{i t}, e_{i t}$ and $\eta_{i t}$, includes the factors $F_{i}, S_{i}$ and $P_{i}$. These factors represent individual effects, (e.g., managerial capacity, differences in accounting methods) that their impact remains constant over time (firm-specific effects). Allowing for subject specific parameters we control for heterogeneity of individuals.

The control variables have been determined in previous sections. In addition, we added to each equation the dependent variable with a time lag as an explanatory variable considering that the previous values of the dependent variables affect their current value. Assuming that the level of each element of working capital is determined simultaneously, the independent estimation of each equation leads to inconsistent estimators (see, e.g. Green, 2003). So we use techniques that are appropriate for systems of simultaneous equations. 
In the presence of fixed-effects, our model can be estimated using either the firstdifferencing of the observations or their mean-centering transformation. We choose for many reasons the transformation of the first differences. The main reason is that using mean-centering transformation of the variables in models that include time lags of the depended variable as explanatory variables estimates of the coefficients are no longer consistent (Wooldridge, 2002). Another reason is that the mean of the variables may change as new data are added per year so the use of the model for forecasts is inappropriate (violation of the instrument's stability assumption).

Therefore, using the transformation of the first differences for each variable, the system of the S1-S3 equations becomes:

$$
\begin{aligned}
& \Delta \log D I H_{i t}=\alpha_{10}+b_{11} \Delta \log D S O_{i t}+b_{12} \Delta \log D P O_{i t}+b_{13} \Delta \log g m_{i t} \\
& +b_{14} \Delta \log _{\text {cint }}{ }_{i t}+b_{15} \Delta \log _{\text {ss }}{ }_{i t}+b_{16} \Delta \log D I H_{i, t-1}+\Delta u_{i t} \\
& \Delta \log D S O_{i t}=\alpha_{20}+\Delta b_{31} \log D P O_{i t}+b_{32} \Delta \log D H I_{i t}+b_{33} \Delta \text { logoldassets } i t \\
& +b_{34} \Delta \log D S O_{i, t-1}+\eta_{i t} \\
& \Delta \log D P O_{i t}=\alpha_{30}+b_{31} \Delta \log D S O_{i t}+b_{32} \Delta \log D H I_{i t}+b_{33} \Delta \log s i z e_{i t} \\
& +b_{34} \Delta \log D P O_{i, t-1}+e_{i t}
\end{aligned}
$$

Where prefix $\Delta$ represents the first differences for each variable. The above equations are the structural equations and the parameters to be estimated the structural parameters. By expressing each endogenous variable as a function of the exogenous variables we obtain the reduced form of the system (equations S4, S5 and S6 as follows):

$$
\begin{aligned}
& S 4: \Delta \log D I H_{i t}=\gamma_{10}+\gamma_{11} \Delta \log D S O_{i, t-1}+\gamma_{12} \Delta \log D P O_{i, t-1}+\gamma_{13} \Delta \log D I H_{i, t-1} \\
& +\gamma_{14} \Delta \text { size }_{i t}+\gamma_{15} \Delta \text { logoldasset }{ }_{i t}+\gamma_{16} \Delta \operatorname{Lloggm}_{i t} \\
& +\gamma_{17} \Delta \log \operatorname{cint}_{i t}+\gamma_{18} \Delta \operatorname{logss} s_{i t}+v_{i t} \\
& \text { S5: } \Delta \log D S O_{i t}=\gamma_{20}+\gamma_{21} \Delta \log D S O_{i, t-1}+\gamma_{22} \Delta \log D P O_{i, t-1} \\
& +\gamma_{23} \Delta \log D I H_{i, t-1}+\gamma_{24} \Delta \text { size }_{i t}+\gamma_{25} \text { Llogoldasset }_{i t} \\
& +\gamma_{26} \Delta \log \operatorname{lom}_{i t}+\gamma_{27} \Delta \log c i_{i t}+\gamma_{28} \Delta \log s_{i t}+\theta_{i t} \\
& \text { S6: } \Delta \log D P O_{i t}=\gamma_{30}+\gamma_{31} \Delta \log D S O_{i, t-1}+\gamma_{32} \Delta \log D P O_{i, t-1} \\
& +\gamma_{33} \Delta \log D I H_{i, t-1}+\gamma_{34} \Delta \text { size }_{i t}+\gamma_{35} \Delta \text { logoldasset } \\
& +\gamma_{36} \Delta \log g m_{i t}+\gamma_{37} \Delta \log c i_{i t}+\gamma_{38} \Delta \log s_{i t}+\omega_{i t}
\end{aligned}
$$

The coefficients $\gamma_{10}$ to $\gamma_{38}$ are functions of the parameters of structural equations $\alpha_{10}$ to $\alpha_{34}$. Using the order condition test, we find that all three equations of the system are over-indentified. Various techniques such as the 3SLS, the full information maximum likelihood method or the generalized method of moments with instrumental variables can be used to estimate the system. The 3SLS method, which is equivalent to FIML giving the assumption that residuals are normally distributed, while produces efficient estimators in the presence of over-indentified 
equations and correlated residuals between the equations, however, requires homoskedastic residuals. The residuals in the system of S4-S6 equations are most likely to be heteroskedastic and autocorrelated as in most cases of panel data analysis of accounting and financial variables. Thus, in this study the generalized method of moments with instrumental variables is used. The estimations that result from this method, given that the condition of normality is satisfied, are the most efficient among all others (Green, 2003). As instrumental variables, we used all the exogenous variables in the system. Although the above estimation methods are well known in terms of simultaneous equation systems, extension to panel data was originally made by Baltagi (1981) by introducing the least squares estimation method in three stages (EC3SLS, error components three-stage least squares). Prucha (1985) introduces the FIML estimator while Cornwell et al. (1992) study the effectiveness of various estimators by distinguishing the presence of random or fixed-effects.

\section{Model estimations of simultaneously determined equations of the working capital components}

The results of the estimations of the system of structural equations allow us to draw conclusions about the relationship between inventories, accounts receivable and accounts payable. For this purpose the estimates of the coefficients $b_{11}, b_{12}, b_{21}, b_{22}$, $b_{31}$ and $b_{32}$ of the system of equations $S 1-S 3$ will be used.

The coefficients of the endogenous variables found statistically significant in all three structural equations allow us to assume that decisions regarding the level of inventories, receivables and payables are simultaneously determined by the working capital managers. We note that the simultaneous determination of the coefficients permits the investigation of the cause-effect relationship between the working capital elements.

Table 4 presents the results of the system estimation of the S1-S3 equations. The effects of all the variables that have chosen in determining the three equations are statistically significant in all cases at CI 99\% ( $\mathrm{p}<0.001)$ except for the $\Delta \log D I H$ variable in the accounts receivable equation which is statistically significant at CI $95 \%(\mathrm{p}=0.028)$.

Table 3. Estimations results of the model of the simultaneously identified equations of the components of working capital Inventories equation: Depended variable $\mathbf{\Delta l o g} D I H$

\begin{tabular}{lrrrr} 
Variables & Coefficients & \multicolumn{1}{c}{ Stand. Error } & \multicolumn{1}{c}{$\mathbf{z}$} & \multicolumn{1}{c}{$\operatorname{Pr}<\mathbf{z}$} \\
\hline$\Delta \log \mathrm{DSO}$ & -0.884 & 0.078 & -11.310 & 0.000 \\
$\Delta \log \mathrm{DPO}$ & 0.817 & 0.053 & 15.510 & 0.000 \\
$\Delta \operatorname{loggm}$ & 0.435 & 0.030 & 14.590 & 0.000
\end{tabular}




\begin{tabular}{|c|c|c|c|c|}
\hline \multicolumn{5}{|c|}{ Inventories equation: Depended variable $\mathbf{A l o g} \boldsymbol{D I H}$} \\
\hline Variables & Coefficients & Stand. Error & $\mathbf{z}$ & $\operatorname{Pr}<\mathbf{z}$ \\
\hline$\Delta \log c i n t$ & -0.126 & 0.009 & -13.600 & 0.000 \\
\hline$\Delta \operatorname{logss}$ & -0.423 & 0.022 & -19.370 & 0.000 \\
\hline$\Delta \log D I H_{t-1}$ & -0.041 & 0.016 & -2.620 & 0.009 \\
\hline Constant & 0.060 & 0.006 & 10.290 & 0.000 \\
\hline \multicolumn{5}{|c|}{ Accounts Receivable equation: Depended variable $\Delta \log D S O$} \\
\hline Variables & Coefficients & Stand. Error & $\mathbf{z}$ & $\operatorname{Pr}<\mathbf{z}$ \\
\hline$\Delta \log \mathrm{DIH}$ & 0.043 & 0.019 & 2.190 & 0.028 \\
\hline$\Delta \log \mathrm{DPO}$ & 0.561 & 0.028 & 19.750 & 0.000 \\
\hline$\Delta$ logoldassets & -0.024 & 0.006 & -4.030 & 0.000 \\
\hline$\Delta \log D S O_{t-1}$ & -0.098 & 0.014 & -7.180 & 0.000 \\
\hline Constant & 0.014 & 0.004 & 3.720 & 0.000 \\
\hline \multicolumn{5}{|c|}{ Accounts Payable equation: Depended variable $\Delta \log D P O$} \\
\hline Variables & Coefficients & Stand. Error & $\mathbf{z}$ & $\operatorname{Pr}<\mathbf{z}$ \\
\hline$\Delta \log \mathrm{DIH}$ & 0.262 & 0.024 & 11.000 & 0.000 \\
\hline$\Delta \log \mathrm{DSO}$ & 0.305 & 0.046 & 6.600 & 0.000 \\
\hline$\Delta \operatorname{logsize}$ & 0.333 & 0.030 & 11.030 & 0.000 \\
\hline \multirow{2}{*}{$\begin{array}{l}\Delta \log D P O_{t-1} \\
\text { Constant }\end{array}$} & -0.194 & 0.011 & -17.470 & 0.000 \\
\hline & -0.025 & 0.005 & -5.020 & 0.000 \\
\hline
\end{tabular}

On the basis of the results of the system's estimations, the following conclusions can be drawn:

\subsection{Relations between inventories and accounts receivable}

The results of the estimation of the coefficients of the receivables equation show that a $1 \%$ increase in the holding period of inventories will result in a minimal increase of $0.043 \%$ of the length of the accounts receivable. This is the direct effect of inventories on receivables. In addition, any changes in the holding period of inventories will result in changes in the length of accounts payable. Changes in accounts payable will in turn result in changes in the level of accounts receivable resulting from the equation of accounts receivable. From the estimates of the accounts receivable equation it is clear that an increase in the period of accounts payable by $1 \%$ will cause a reduction in receivables period by $0.561 \%$. This is the indirect effect of the effect of inventories on receivables. Quantitatively, the indirect effect of inventories is calculated from the product of inventories 
coefficient in the equation of the accounts payable $(=0.262)$ to the value of the coefficient of accounts payable to the accounts receivable equation $(=0.561)$, i.e.:

$$
\text { "inDIH } \stackrel{\text { DPO }}{\longrightarrow} D S O "=(0.262)(0.561)=0.147
$$

where $" \mathrm{inDIH} \stackrel{D P O}{\longrightarrow} D S O "$ is the indirect effect of changes in inventory turnover on the accounts receivable turnover through the changes in accounts payable that have been caused by the changes in inventory turnover.

The direct effect of inventory changes in accounts receivable, let it be "diDIH $\rightarrow$ $D S O "$, as mentioned above, is represented by the value of the coefficient of $\triangle \log D I H$ in the accounts receivable equation and is:

$$
" d i D I H \rightarrow D S O "=0.043
$$

The total effect of changes in inventory turnover on the accounts receivable period, let it be"totalDIH $\rightarrow D S O "$, is the sum of the direct and indirect effects:

$$
" \text { totalDIH } \rightarrow \text { DSO" = "diDIH } \rightarrow D S O "+\text { "inDIH } \stackrel{D P O}{\longrightarrow} D S O "=0.043+(0.147)=0,190
$$

The value of the total effect shows that a $1 \%$ increase in $D I H$ will result in a total increase in $D S O$ by $0.19 \%$

Using as previously the same terminology, the overall effect of $D S O$ on $D I H$, will be:

$$
\begin{array}{r}
" t o t a l D S O \rightarrow D I H "=" d i D S O \rightarrow D I H "+" i n D S O \stackrel{D P O}{\longrightarrow} D I H^{\prime \prime} \\
=-0.884+(0.305)(0.817)=-0.635
\end{array}
$$

The value of the total effect, -0.635 , practically means that any changes in accounts receivable period will have a substantial effect on inventory turnover. $1 \%$ increase in DSO will result in a decrease of $0.635 \%$ in DIH. However, $1 \%$ increase in DIH cause an increase of $0.190 \%$ in DSO.

\subsection{Relations between inventories and accounts payable}

Following the same procedure as above, we calculate the total impact of inventories on the accounts payable:

$$
\begin{array}{r}
\text { totalDIH } \rightarrow \text { DPO }=d i D I H \rightarrow D P O+i n D I H \stackrel{D S O}{\longrightarrow} D P O \\
=0.262+(0.043)(0.305)=0,275
\end{array}
$$


While the total impact of accounts payable on inventory period is:

$$
\begin{array}{r}
\text { totalDPO } \rightarrow D I H=" d i D P O \rightarrow D I H^{\prime \prime}+" \text { inDPO } \stackrel{D S O}{\longrightarrow} D I H^{\prime \prime} \\
=0.817+(0.561)(-0.884)=0,321
\end{array}
$$

\subsection{Relations between accounts receivable and accounts payable}

The effect of accounts receivable on accounts payable period is:

$$
\begin{gathered}
" \text { totalDSO } \rightarrow \text { DPO" }=" d i D S O \rightarrow D P O "+" \text { inDSO } \stackrel{D I H}{\longrightarrow} D P O " \\
=0.305+(-0.884)(0.262)=0,073
\end{gathered}
$$

On the other hand the impact of accounts payable to accounts receivable is:

$$
\begin{aligned}
& \text { totalDPO } \rightarrow \text { DSO }=" d i D P O \rightarrow D S O "+" \text { inDPO } \stackrel{D I H}{\longrightarrow} D S O " \\
& \quad=0.561+(0.817)(0.043)=0.596
\end{aligned}
$$

Summarizing, the simultaneous effects of the working capital components to each other are as follows:

1. Effect of inventories holding period on accounts receivable period $\quad: 0.190$

2. Effect of inventories holding period on accounts payable period $\quad: 0.275$

3. Effect of accounts receivable period on accounts payable period $: 0.073$

4. Effect of accounts receivable period on inventories holding period $:-0.635$

5. Effect of accounts payable period on accounts receivable period $\quad: 0.596$

6. Effect of accounts payable period on inventories holding period $\quad: 0.321$

Estimates from reduced form equations are presented at Table 5 below. All coefficients are statistically significant at $\mathrm{p}<0.001$ except the coefficient of the lag of $\triangle \log D P O$ which is not statistically significant at inventories and receivables

\begin{tabular}{|c|c|c|c|c|c|c|}
\hline & \multicolumn{2}{|c|}{$\triangle \log D I H$} & \multicolumn{2}{|c|}{$\triangle \log D S O$} & \multicolumn{2}{|c|}{$\triangle \log D P O$} \\
\hline & Coef. & $\mathrm{p}$-value & Coef. & $\mathrm{p}$-value & Coef. & $\mathrm{p}$-value \\
\hline$\Delta \log D I H_{t-1}$ & -0.081 & 0.000 & 0.032 & 0.000 & 0.016 & 0.268 \\
\hline$\Delta \log D P O_{t-1}$ & -0.009 & 0.326 & -0.010 & 0.145 & -0.223 & 0.000 \\
\hline$\Delta \log D S O_{t-1}$ & 0.103 & 0.000 & -0.053 & 0.000 & 0.101 & 0.000 \\
\hline Aoldassets & 0.382 & 0.000 & -0.091 & 0.000 & 0.072 & 0.000 \\
\hline
\end{tabular}
equations. The reduced form equations allow us to generate forecasts of each of the components of cash conversion cycle after controlling for the impact of the exogenous variables given the contemporaneous effects of the endogenous variables.

Table 4. Estimation Results of Reduced Form Equations. 


\begin{tabular}{lcccccc}
\hline & \multicolumn{2}{c}{ AlogDIH } & \multicolumn{2}{c}{ AlogDSO } & \multicolumn{2}{c}{ AlogDPO } \\
& Coef. & p-value & Coef. & p-value & Coef. & p-value \\
\hline Asize & 0.068 & 0.002 & 0.538 & 0.000 & 0.541 & 0.000 \\
Alogcint & -0.471 & 0.000 & 0.074 & 0.000 & -0.091 & 0.000 \\
Aloggm & 0.328 & 0.000 & 0.242 & 0.000 & 0.138 & 0.000 \\
4logss & -0.384 & 0.000 & -0.304 & 0.000 & -0.234 & 0.000 \\
cons & 0.074 & 0.000 & 0.010 & 0.001 & -0.003 & 0.516 \\
\hline
\end{tabular}

We summarize some of the insights from these estimates as below. Our results indicate that while the effect of average collection period on inventory holding period is negative (which is consistent with the findings of other studies e.g. Bougheas et al., 2009), the effect of inventory holding period on average collection period of receivables is positive.

The coefficient of gross margin is positive and statistically significant at all equations indicating the negative effect of gross margin in inventory turnover (times). This finding is in accordance with the results in many inventory studies (e.g. Gaur et al., 2005; Rumyantsev \& Netessine 2007; Kolias et al. ,2011; Hançerlioğulları et al., 2016) point out that higher gross margin induce firms to increase inventory turnover ratio.

According to our results firm size affects positively both accounts receivable and payable. Related studies (e.g. Grablowsky, 1976 and Petersen \& Rajan, 1997) indicate that large firms that have the ability to analyze their customers' creditworthiness and because of their size are more risk tolerance, use accounts receivable more effectively and efficiently. The same conclusion is reached by $\mathrm{Ng}$ et al. (1999) arguing that economies of scale influence the level of accounts receivable. In addition, the authors argue that the cost of collecting information and the complexity of evaluating credit terms allow larger businesses to extend credit to their customers over smaller ones.

There is a positive effect of inventories to accounts receivable. Probably firms that are faced with accumulation and longer inventory period will reduce their suppliers' orders and increase the amount of accounts receivable to support increased sales. There is a positive effect of inventories to accounts payable. This means that wholesalers largely finance investment in stocks with trade credit. The funds required to finance longer inventory periods caused either by greater investment in stocks or by a fall in sales growth rates than in inventory growth rate or both, are raised through trade credit.

The total impact of accounts payable on inventory period is estimated to be positive. The result shows that the potential of extending credits by suppliers maybe increase the 
length of inventory period either by increasing the cost of sales to the wholesaler due to non-acceptance of discounts or by allowing them to purchase a wider variety of goods. Our results also show that companies with a high level of accounts receivable also have a low level of inventory. This may be because while the company suffering a longer collection period could offset the impact by ordering too little and reducing inventory levels.

\section{Conclusion}

Although there is a substantial amount of existing literature on inventory management and trade credit decisions, few attempts have been made to integrate cash conversion cycle management. Since there is no integrated model to optimize working capital investment (Zeidan \& Shapir, 2017), improving cash conversion cycle requires the analysis of the interrelations of its features. To this end, we construct a simultaneous equations system to examine the interrelationships among inventories, accounts receivable and accounts payable. The model we developed let the separation of the direct and indirect effects of each component of cash conversion cycle on the remaining. In general, the complexity of the relationships between working capital elements is confirmed. Besides, the system of simultaneous equations permits us to verify the directions of causality among cash conversion cycle elements. The results of this study would be useful for wholesalers and supply chain managers to understand and analyze the interactions of inventory management and trade credit which will allow them to better plan their value-added strategy.

Additionally, our model demonstrates how potential changes in variables indicate firm policy (e.g. gross margin) and managerial ability (e.g. sales forecasting) can affect the level of inventories, accounts receivable and accounts payable of the firm. Moreover, using the reduced form equations, more accurate forecasts can be produced. These equations include exogenous variables and lagged endogenous variables to forecast inventory, accounts receivables and accounts payables simultaneously. Changes in working capital elements affect the operating cash flows of businesses. Therefore, accurate estimations of changes in these items leads to better forecasting of cash flows. Finally, our model can be utilized in future research for the prediction of firm cash flows. 


\section{References}

Adhikari, H. P., Krolikowski, M. W., Malm, J., \& Sah, N. B. (2019) "Working capital (mis) management-impact of executive age, Accounting \& Finance, in press

Baltagi, B. H. (1981) "Simultaneous equations with error components", Journal of econometrics, vol. 17(2): 189-200

Belt, B. (1979) "Working Capital policy and liquidity in the small business", Journal of Small Business Management, vol. 17: 43-51

Birge, J., Kouvelis, P., \& Seppi, D. (Eds.) (2007) Call for Papers-Special Issue of Management Science: Interfaces of Operations and Finance. Management Science, vol. 53(2): 355-355.

Bougheas, S., Mateut, S., \& Mizen, P. (2009) "Corporate trade credit and inventories: New evidence of a trade-off from accounts payable and receivable", Journal of Banking \& Finance, vol. 33(2): 300-307.

Caniato, F., Gelsomino, L. M., Perego, A., \& Ronchi, S. (2016) "Does finance solve the supply chain financing problem?", Supply Chain Management: An International Journal, vol. 21(5): 534-549

Carnovale, S., Rogers, D. S., \& Yeniyurt, S. (2019) "Broadening the perspective of supply chain finance: The performance impacts of network power and cohesion", Journal of Purchasing and Supply Management, val. 25(2): 134-145.

Cornwell, C., Schmidt, P., \& Wyhowski, D. (1992) "Simultaneous equations and panel data", Journal of Econometrics, vol. 51 (1-2): 151-181.

Ferrando, A., \& Mulier, K. (2013), "Do firms use the trade credit channel to manage growth?", Journal of Banking \& Finance, vol. 37, (8): 3035-3046.

Gaur, V., Fisher, M., \& Raman, A. (2005) "An econometric analysis of inventory turnover performance in retail services", Management Science, vol. 51, no. 2: 181-194.

Gentry, J. A., \& De La Garza, J. M. (1990) "Monitoring accounts payables", Financial Review, vol. 25(4): 559-576.

Grablowsky, B. J. (1976) "Mismanagement of accounts receivable by small businesses", Journal of Small Business Management (pre-1986), vol. 14(4): 23

Greene, W. H. (2003) Econometric analysis, Pearson Education India.

Gupta, S., \& Dutta, K. (2011) "Modeling of financial supply chain", European Journal of Operational Research, vol. 211 (1): 47-56.

Hager, H. C. (1976) "Cash management and cash cycle", Management Accounting, vol. 57: 19-21

Hill, M.D., Kelly, G.W., Highfield, M.J., 2010. Net operating working capital behavior: a first look. Financ. Manag. vol. 39: 783-805

Jia, F., Blome, C., Sun, H., Yang, Y., \& Zhi, B. (2019) "Towards an integrated conceptual framework of supply chain finance: An information processing 
perspective", International Journal of Production Economics, vol. 218: 19-30

Kolias, G., \& Arnis, N. (2019) "The optimal allocation of current assets using mean-variance analysis", Accounting and Management Information Systems, vol.18, no.1: 50-72

Kolias, G. D., Dimelis, S. P. \& Filios, V. P. (2011) "An empirical analysis of inventory turnover behaviour in Greek retail sector: 2000-2005", International Journal of Production Economics, vol. 133 (1):143-153.

Kotler, P. (1980) "Strategic planning and the marketing process", Business, vol. 30, no 3: 2-9

Lee, H. H., Zhou, J., \& Hsu, P. H. (2015) "The role of innovation in inventory turnover performance", Decision Support Systems, vol. 76: 35-44.

Morris, J.R. (1983) "The Role of cash balances in Firm Valuation", Journal of Financial and Quantitative Analysis, vol. 18: 533-545.

Ng, C. K., Smith, J. K., \& Smith, R. L. (1999) "Evidence on the determinants of credit terms used in interfirm trade", The journal of finance, vol. 54 (3): 1109-1129.

Opler, T., L. Pinkowitz, L., Stulz, R. \& Williamson, R. (1999) "The determinants and implications of cash holdings", Journal of Financial Economics, vol. 52: 3-46

Petersen, M. A., \& Rajan, R. G. (1997) "Trade credit: theories and evidence”, The Review of Financial Studies, vol. 10 (3): 661-691

Protopappa-Sieke, M., \& Seifert, R. W. (2010) "Interrelating operational and financial performance measurements in inventory control", European Journal of Operational Research, vol. 204 (3): 439-448

Prucha, I. R. (1985) "Maximum likelihood and instrumental variable estimation in simultaneous equation systems with error components", International Economic Review, vol. 26(2): 491-506

Rajagopalan, S. (2013) "Impact of variety and distribution system characteristics on inventory levels at US retailers", Manufacturing \& Service Operations Management, vol. 15(2): 191-204

Richards, V.D. \& Laughlin, E.J. (1980) "A cash conversion cycle approach to liquidity analysis", Financial Management, vol. 9: 32-38

Wang, B. (2019) "The cash conversion cycle spread", Journal of Financial Economics, vol. 133(2): 472-497

Wooldridge, J. M. (2002) Econometric analysis of cross section and panel data, Cambridge: MIT Press

Zeidan, R. \& Shapir, O.M. (2017) "Cash conversion cycle and value-enhancing operations: theory and evidence for a free lunch", Journal of Corporate Finance, vol. 45, 203-219. 


\section{Appendix}

\begin{tabular}{ccc}
\multicolumn{2}{c}{ Number of firms in the Greek Wholesale Sector by NACE code } \\
$\begin{array}{ccc}\text { NACE_1_1_C } \\
\text { ODE }\end{array}$ & Description & \# of \\
\end{tabular}

Agents involved in the sale of fuels, ores, metals and industrial

$51.12 \quad$ chemicals 40

Agents involved in the sale of machinery, industrial equipment,

$\begin{array}{lll}51.14 & \text { ships and aircraft } & 57\end{array}$

$\begin{array}{lll} & \text { Agents involved in the sale of furniture, household goods, } \\ \text { 51.15 } & \text { hardware and ironmongery } & 10\end{array}$

51.17 Agents involved in the sale of food, beverages and tobacco 20

$\begin{array}{ll}\text { 51.18 } & \text { Agents specialising in the sale of particular products or ranges of } \\ \text { products n.e.c. }\end{array}$

51.19 Agents involved in the sale of a variety of goods 33

$\begin{array}{lll}51.21 & \text { Wholesale of grain, seeds and animal feeds } & 148\end{array}$

$\begin{array}{lll}51.22 & \text { Wholesale of flowers and plants } & 20\end{array}$

$\begin{array}{lll}51.24 & \text { Wholesale of hides, skins and leather } & 10\end{array}$

$\begin{array}{lll}51.31 & \text { Wholesale of fruit and vegetables } & 170\end{array}$

$\begin{array}{lll}51.32 & \text { Wholesale of meat and meat products } & 190\end{array}$

$51.33 \quad$ Wholesale of dairy produce, eggs and edible oils and fats 80

$51.34 \quad$ Wholesale of alcoholic and other beverages 230

$\begin{array}{lll}51.35 & \text { Wholesale of tobacco products } & 10\end{array}$

$\begin{array}{lll}51.36 & \text { Wholesale of sugar and chocolate and sugar confectionery } & 87\end{array}$

51.37 Wholesale of coffee, tea, cocoa and spices 30

51.38 Wholesale of other food, including fish, crustaceans and molluscs $\quad 426$

51.39 Non-specialised wholesale of food, beverages and tobacco 7

$\begin{array}{lll}51.41 & \text { Wholesale of textiles } & 170\end{array}$

$51.42 \quad$ Wholesale of clothing and footwear 330

$51.43 \quad$ television goods 388

$\begin{array}{lll}51.44 & \text { Wholesale of china and glassware, wallpaper and cleaning } \\ \text { materials } & 110\end{array}$

$\begin{array}{lll}51.45 & \text { Wholesale of perfume and cosmetics } & 90\end{array}$

$\begin{array}{lll}51.46 & \text { Wholesale of pharmaceutical goods } & 111\end{array}$

$51.47 \quad$ Wholesale of other household goods 488

$51.51 \quad$ Wholesale of solid, liquid and gaseous fuels and related products 93

$51.52 \quad$ Wholesale of metals and metal ores 230

W1.53 Wholesale of wood, construction materials and sanitary equipment 477 


\begin{tabular}{llr}
\hline $\begin{array}{c}\text { NACE_1_1_C } \\
\text { ODE }\end{array}$ & \multicolumn{1}{c}{ Description } & $\begin{array}{r}\text { \# of } \\
\text { firms }\end{array}$ \\
\hline 51.54 & Wholesale of hardware, plumbing and heating equipment and & 444 \\
51.55 & supplies & 556 \\
51.56 & Wholesale of chemical products & 131 \\
51.57 & Wholesale of other intermediate products & 10 \\
51.81 & Wholesale of waste and scrap & 47 \\
51.82 & Wholesale of machine tools & 80 \\
51.84 & Wholesale of mining, construction and civil engineering machinery & \\
51.85 & Wholesale of computers, computer peripheral equipment and & 268 \\
51.86 & Software & 58 \\
51.87 & Wholesale of other office machinery and equipment & 347 \\
51.88 & Wholesale of other electronic parts and equipment & 1088 \\
& Wholesale of other machinery for use in industry, trade and & 143 \\
& navigation & 8240 \\
\hline
\end{tabular}

\footnotetext{
${ }^{1}$ Hager (1976) was the first to introduce the cash cycle, stating that its duration arises if from the total duration of the productive cycle the average duration of the accounts payable is subtracted, arguing that the uncertainty of the productive cycle requires a certain degree of liquidity and that the short duration of the cash cycle when coupled with inexpensive sources of capital leads to maximizing business returns.

Belt (1979) in his study of small business behavior also argues that their liquidity should rather be assessed on the basis of the degree of convenience of converting inventories and cash requirements, sales forecasts and debt structure, rather than the difference in working capital with short-term liabilities.

Richards and Laughlin (1980) introduce the concept of cash conversion cycle, a concept identical to that of Hager's (1976) proposal, arguing that the assessment of business liquidity based on the traditionally used liquidity ratios is likely to lead to misleading conclusions. They argued that analyzing the cash conversion cycle can lead to the proper management of working capital in terms of time and amounts needed to meet liquidity needs.

The cash conversion cycle index, ccc, is calculated as follows:

$\mathrm{CCC}=$ Days of Receivables + Days of Inventory - Days of Payables
} 